\title{
BMJ Open Psychometric properties of the Arabic version of the 9-item Shared Decision- Making Questionnaire: the entire process from translation to validation
}

\author{
Hamzah Alzubaidi, ${ }^{1}$ Amal Hussein, ${ }^{2}$ Kevin Mc Namara, ${ }^{3}$ Isabelle Scholl ${ }^{4}$
}

To cite: Alzubaidi $\mathrm{H}$, Hussein A, Mc Namara K, et al. Psychometric properties of the Arabic version of the 9-item Shared DecisionMaking Questionnaire: the entire process from translation to validation. BMJ Open 2019;9:e026672. doi:10.1136/ bmjopen-2018-026672

- Prepublication history for this paper is available online To view these files, please visit the journal online (http://dx.doi org/10.1136/bmjopen-2018026672).

Received 13 September 2018 Revised 4 February 2019 Accepted 5 February 2019

Check for updates

(C) Author(s) (or their employer(s)) 2019. Re-use permitted under CC BY-NC. No commercial re-use. See rights and permissions. Published by BMJ.

${ }^{1}$ College of Pharmacy, Sharjah Institute for Medical Research, University of Sharjah, Sharjah, United Arab Emirates

${ }^{2}$ Family and Community

Medicine \& Behavioral Sciences, University of Sharjah, College of Medicine, Sharjah, United Arab Emirates

${ }^{3}$ Deakin University, Burwood,

Victoria, Australia

${ }^{4}$ Department of Medical

Psychology, University Medical Center Hamburg-Eppendorf, Hamburg, Germany

Correspondence to

Dr Hamzah Alzubaidi;

halzubaidi@sharjah.ac.ae

\section{ABSTRACT}

Objective To translate the German 9-item Shared Decision-Making Questionnaire (SDM-Q-9) to Arabic and assess its psychometric properties for measuring Arabicspeaking patients' perceptions of the shared decisionmaking (SDM) process.

Design Multicentre cross-sectional study.

Setting Secondary healthcare settings; outpatient clinics of 10 major hospitals were selected in four emirates in the United Arab Emirates (Abu Dhabi, Dubai, Sharjah and Umm Al Quwain).

Participants Patients with chronic diseases who attended outpatient clinics of participating hospitals.

Measurements The original German SDM-Q-9 was translated to Arabic. International multiphase translation guidelines and the process of cross-cultural adaptation of self-reported measures were used. Various psychometric properties were assessed, including reliability (internal consistency), and construct validity (exploratory factor analysis [EFA] and confirmatory factor analysis [CFA]). Results The final Arabic version of the SDM-Q-9 was tested among 516 secondary care patients. Internal consistency yielded a Cronbach's alpha of 0.929 for the whole scale. EFA showed a one-factorial solution, Kaiser-Meyer-Olkin measure of sampling adequacy was 0.907 and Bartlett's test of sphericity was significant $\left(\chi^{2}=3413.69, d f=36, p<0.0005\right)$. For the CFA, two different models were tested; Model 1 included the nine items and Model 2 was monofactorial that included items 2-9 and thus excluded item 1. Both models were adequate as they produced similar indices.

Conclusions The Arabic version of SDM-Q-9 showed excellent reliability and acceptable validity parameters among secondary care patients. The newly translated Arabic questionnaire is the first psychometrically tested tool that can be used in the 22 member states of the Arab league to assess patients' perspectives on the SDM process.

\section{INTRODUCTION}

The importance of active patient participation during clinical decision-making is gaining increasing emphasis in modern healthcare policy. ${ }^{1}$ Shared decision-making (SDM) has been advocated as a key model of treatment

\section{Strengths and limitations of this study}

- One major strength of this work is the potential for the Arabic version of 9-item Shared DecisionMaking Questionnaire to be used by the 407 million people who make up the populations of all the Arab states.

- The convenience sampling may not be representative of the entire population attending secondary healthcare settings.

- The large sample size and the diversity of study participants increases the likelihood of results being representative.

- The use of a self-reported measure in this study does not eliminate the possibility of an inaccurate recall of respondents' experiences and opinions.

decision-making. ${ }^{2}$ The SDM process takes into account patients' preferences and opinions, and clinicians work collaboratively with patients in making treatment decisions. ${ }^{3}$ The extent to which SDM is applied in routine medical encounter varies. Research showed that the SDM, when applied, promotes patient autonomy, limits practice variation and ensures that treatment decisions are guided by patient preferences. ${ }^{4-6}$ Patients are increasingly encouraged to assume active roles as managers of their own health and not merely the recipients of services or advice. ${ }^{78}$ This growing interest in SDM has been driven by several factors including (1) the increasing accessibility of health information facilitates participation by patients in medical decision-making by asking informed questions and expressing their personal values and opinions regarding prescribed treatment, (2) clinicians are increasingly respecting patients' goals and preferences and willing to use these to guide their recommendations and treatments and (3) rapidly changing societal norms where patients are demanding more autonomy. ${ }^{9-11}$ However, barriers to use 
of SDM in routine clinical practice remain extensive. ${ }^{12}$ Knowledge alone is insufficient to empower patients to share in decisions-a power imbalance remains between patients and clinicians, and active clinician support for patients to engage in SDM is required.$^{13}$ Unfortunately, even when clinicians are open to considering patients' values and preferences, they typically remain under skilled to do so despite self-perceptions of competency. ${ }^{2}$ They believe that they do not have the time to incorporate SDM as a routine practice, and they underestimate patient's desire and capacity to engage in SDM. ${ }^{145}$

The evidence regarding health benefits of SDM is unclear-this may reflect a variety of factors including an incomplete understanding about how to optimise SDM interventions, the heterogeneity of contexts in which trials were performed (eg, if no treatment option discussed is clearly superior in terms of intended effect) or patients prioritising quality of life over narrow clinical benefits. ${ }^{16}$ Despite the lack of clarity around clinical effectiveness, there is a clear ethical imperative to incorporate SDM into practice. It is an essential component of patient-centred care, and there may also be a modest benefit in reducing the quality of care gap for vulnerable patients who are more likely to suffer from a power imbalance in the clinical relationship. ${ }^{17}$ Patients' experiences with the healthcare systems have also improved as a result of SDM, as patients were more likely to attend appointments and had fewer complaints. ${ }^{18}$ SDM has been shown to significantly reduce healthcare costs by reducing the length of hospital stays and the rates of invasive procedures, as informed patients often tend to choose more conservative approaches. ${ }^{19} 20$

With the growing emphasis on patient involvement in clinical decision-making, there is a high need for valid and reliable tools to assess the quality of the SDM process. This is reflected in the emergence of several tools that measure various aspects of the decision-making processes, such as factors surrounding the task of decision-making, the decision-making process itself and decision outcomes. The content, characteristics and perspective assessed by instruments should be considered when choosing the most appropriate instrument. Existing tools evaluate the decision-making process from the perspective of patients, providers or external observers. While most instruments have shown acceptable reliability, there is significant variability in the extent of validity testing. A recent systematic review assessed the measurement quality of existing SDM tools. ${ }^{6}$ A total of 40 instruments were included, in this review, and results on the best evidence synthesis were inconclusive or unknown for $50 \%$ or more for the measurement psychometric properties mainly due to poor methods. ${ }^{6}$ We chose the 9-item Shared Decision Making Questionnaire (SDM-Q-9), as we wanted to have a patient-reported SDM measure in Arabic that has both good psychometric properties and that has been widely used. ${ }^{21}$ The SDM-Q-9 has been translated into more languages than any other SDM measure and has been used in a large amount of studies. ${ }^{22}{ }^{23}$ It is a unidimensional self-report measure that assesses patient perceptions of the decision-making process in a specific medical encounter. The SDM-Q-9 has been translated into several languages from the original German and has consistently demonstrated good reliability and validity. ${ }^{24}$ It is a brief tool that consists of nine items, each asking about one step of the SDM process. ${ }^{25}$ For each item, respondents indicate their level of involvement in SDM on a six-point Likert scale (from $0=$ completely disagree to $5=$ completely agree). The scale was originally developed in German, and no Arabic version exists. A recent review of the literature concluded that the SDM-Q-9 can and has been used to assess interventions aimed at improving the quality of SDM in a wide range of fields. ${ }^{22}$

Conventionally, SDM research has been conducted in western countries; however, recently more research is being undertaken in other regions of the world including Arabic-speaking countries. There appears to be a positive attitude towards SDM among Arabic-speaking professionals and patients, yet further studies are needed to assess the extent to which this model is implemented as a routine daily medical practice. Results of a recent study among 236 Saudi Arabic-speaking patients showed that Saudi patients generally have a positive attitude towards active participation in clinical decision-making. ${ }^{26}$ No valid tool was used to assess patients' preferences for SDM process; participants were given three options to select the most preferred decision-making style. ${ }^{26}$ These were (1) 'consumerist' style when the final decision is made by the patient and his/her family members without physicians, (2) 'paternalistic' approach where the final decision is made by the physician only and (3) SDM style where the decision is jointly made by patient and physician. ${ }^{26}$ Results demonstrated that SDM was the most preferred style followed by the paternalistic approach, while the consumerist approach was the least preferred.$^{26}$ Patients' views on participation in SDM were obtained only from one family practice centre in Saudi Arabia, which represents a major limitation of this study. ${ }^{26}$ To date, there is no validated Arabic-language tool that measures patients' perspectives on SDM. The aim of this study was to translate and assess the psychometric properties of an Arabic version of the SDM-Q-9 that measures the process of SDM in medical encounters from Arabic-speaking patient's perspective.

\section{METHODS \\ Study design and setting}

A cross-sectional survey was conducted at the outpatient clinics of 10 major hospitals in four emirates in the UAE; namely Abu Dhabi, Dubai, Sharjah and Umm Al Quwain. The hospitals were purposefully selected as they are visited by large numbers of Arabic-speaking patients with chronic diseases.

\section{Questionnaire development}

Translation and adaptation of SDM-Q-9

To adapt the scale for use in Arabic-speaking populations, the five-step approach described by Beaton $e t a l^{2}$ 
for cross-cultural adaptation of health status self-report measures was used. First, the original German scale was sent to two independent certified professional translators to translate the original questionnaire from German into Arabic. Second, the two Arabic translations were synthesised by HA and WS and consensus was reached on the translation of words, phrases and items. In the third step, content validity and cultural appropriateness testing of the synthesised Arabic version were done by pilot testing the Arabic version of SDM-Q-9 with two family medicine physicians, one psychologist and one sociologist. These professionals reviewed the content validity, appropriateness and understandability of each item. In the fourth step, feedback from pilot testing was incorporated and the revised Arabic version was then back-translated to German by a third independent and certified translator. In the final step (equivalence testing), the back-translation was sent to the original author (IS) to review and compare the original German version and the back-translated version in German of the SDM-Q-9. Minor discrepancies were identified and resolved by discussion between the researchers and the translators. After minor revisions, the final Arabic version of SDM-Q-9 (table 1) was deemed equivalent to the original German tool and was approved by IS. The final version of the Arabic tool was then pilot tested with four members of the target population (Arabic-speaking adults with chronic diseases). This process ensured face and content validity of the questionnaire and the understandability of all items. No further modifications were necessary.

\section{Study participants and procedure}

Patients attending outpatient clinics in the selected hospitals were approached while waiting for their appointments. Patients were screened for eligibility to participate, and those who met inclusion criteria (self-identified as Arabic-speaking [Arabic was their first language], had at least one chronic disease and were over 18 years of age) were invited to complete the survey. Research objectives were explained to eligible participants, each received a full written explanation of the study and those who agreed to participate signed an informed consent sheet. During pilot testing, participants were asked to complete the survey after attending their medical appointments; however, people were unwilling to wait and complete the survey. Therefore, participants completed an anonymous self-administered questionnaire, while awaiting their medical appointment, without the presence of their treating clinicians. Participants were asked to rate a prior consultation and answered several questions about SDM. The survey had other sections, including (1) sociodemographic section (age, country of birth, sex, marital status, educational level and employment status), (2) health-related data included self-reported health status and comorbidity. Two questions assessed each patient's preferred sources of information and whether (or not) they had any unanswered questions about their condition/treatment and (3) functional health literacy was assessed using
Table 1 The Arabic version of the 9-item Shared Decision-

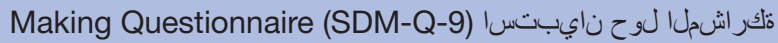

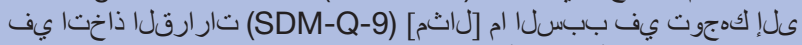

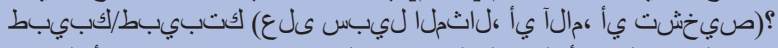

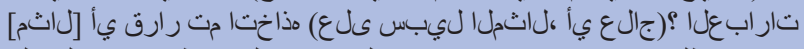

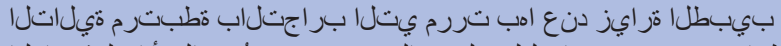

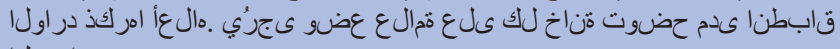

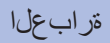

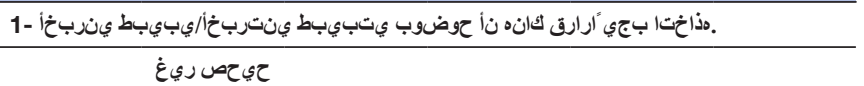
حيحص ىلإحيحص ىلإحيحص حئحصريغ

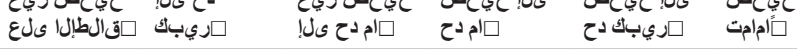

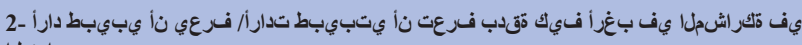

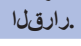

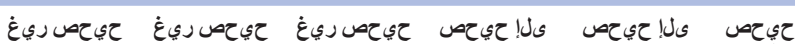

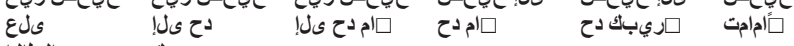

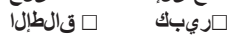

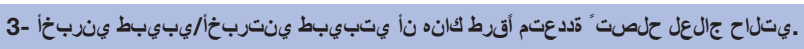

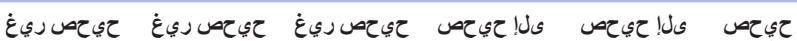

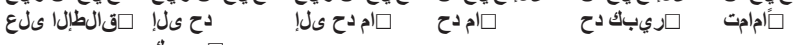

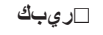

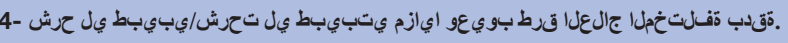

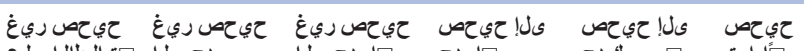

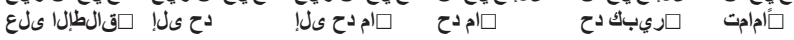

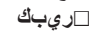

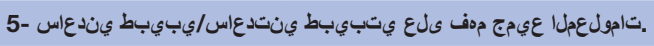

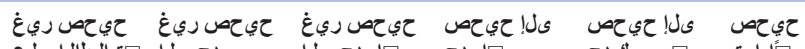

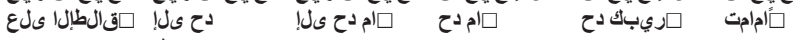
ماريك

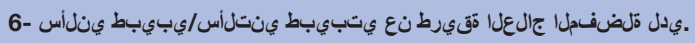

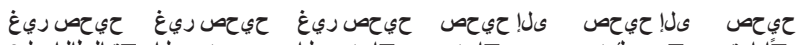

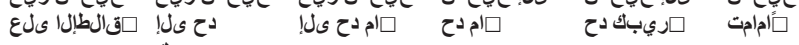
لمريبك

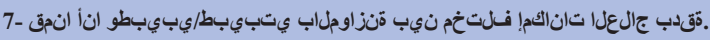
غ ع ع ع

\begin{tabular}{|c|c|c|c|c|c|}
\hline مقآطإل رى رئ & [ـريك & حي امص درى ىل! & 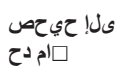 & ىل! حي حص دح & "أيحصص \\
\hline
\end{tabular}

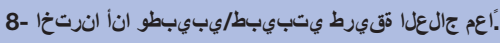

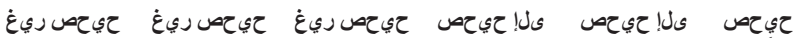

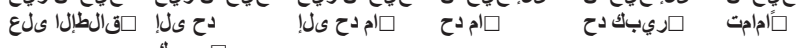
لمريبك

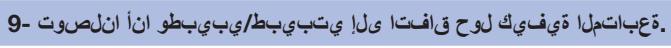

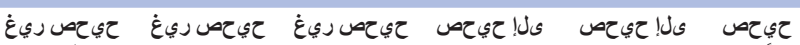

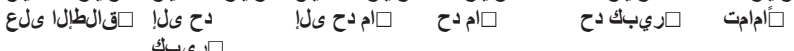
لمريبك

three previously validated items that measured difficulties in reading medical forms or learning about medical conditions. ${ }^{27}$ Inadequate health literacy was indicated if the total score of the three items was $\leq 10$ out of a possible total of 15 .

\section{Patient and public involvement}

Patients and/or public were not involved in the design or planning of the study.

\section{Sample size}

As there are no standard sample size requirements for conducting a validation study, the sample size was obtained using the formula of sample size calculation for a cross-sectional study. The estimated proportion was set at $50 \%$ in order to maximise the value of the minimum 
sample size needed. Level of confidence was set at $95 \%$, type 1 error at $5 \%$ and margin of error at $5 \%$. Sample size calculation yielded a value of 385 subjects. To compensate for potential missing data, this number was increased by $20 \%$ resulting in a minimum required sample size of 462 .

\section{Data analysis}

Item analysis was completed by reporting the descriptive statistics pertaining to each item. Frequencies, percentages, means and SD were reported for each item. Percentage of subjects responding to the 'completely agree' option was reported as a ceiling effect for each item. Scale reliability was measured using the internal consistency of subjects' responses on the scale items and Cronbach's alpha was reported. Corrected item-total correlations were reported for each item on the SDM-Q-9 scale.

The dimensionality of the SDM-Q-9 scale was assessed by conducting the exploratory factor analysis (EFA) using the principal components analysis (PCA), with oblimin rotation, whereby components with Eigenvalues higher than 1 were extracted. Kaiser-Meyer-Olkin test was used to check for sampling adequacy where a minimum value of 0.5 indicated that factor analysis was appropriate. Bartlett's test of sphericity was used to check whether the variables were correlated in an identity matrix. A significant $p$ value associated with the Bartlett's test indicated adequacy of factor analysis.

Confirmatory factor analysis (CFA) was then conducted in order to check how well the factor structure, identified in the EFA, fits the observed data. CFA was performed following the five steps of model specification, identification, estimation, assessment and respecification. The goodness of fit indices, that were used to check whether the data fit with the proposed models, included comparative fit indices (CFI), goodness of fit index (GFI), root mean square error of approximation (RMSEA) and root mean square residual (RMR). GFI and CFI values above 0.90 and RMR and RMSEA values below 0.05 indicated that the CFA model was a good fit. Data were entered, cleaned and analysed using the Statistical Package for Social Sciences (SPSS V.24.0). ${ }^{28}$ All statistical analyses were performed using SPSS except for CFA which was conducted using IBM AMOS V.25.0.

\section{RESULTS}

\section{Participants' characteristics}

A total of 516 participants were recruited and completed the questionnaire. The vast majority of participants were aged between 31 and 60 years with an estimated mean of $45(\mathrm{SD} \pm 13.8)$. They were a mix of both Emirati $(76 \%)$ and Arab expat born in different Arab countries. Of the total sample, $56 \%$ were females, $45 \%$ had a university degree; however, $61 \%$ had inadequate health literacy. Only $42 \%$ reported having a full-time job. When participants were asked how often they had unanswered questions regarding their condition/treatment, $48 \%$ reported either 'always' or 'sometimes'. Around $91 \%$ of participants were interested
Table 2 Participant's characteristics $(n=516)$

\section{Participants' \\ characteristics}

n (\%)

\begin{tabular}{|c|c|c|}
\hline \multirow[t]{2}{*}{ Gender } & Male & 225 (43.6) \\
\hline & Female & 291 (56.4) \\
\hline \multirow[t]{5}{*}{ Age (years) } & $18-30$ & $89(17.2)$ \\
\hline & $31-45$ & 175 (33.9) \\
\hline & $46-60$ & 177 (34.3) \\
\hline & $61-75$ & $75(14.5)$ \\
\hline & $45^{\star}(S D \pm 13.8)$ & \\
\hline \multirow[t]{2}{*}{ Country of birth } & United Arab Emirates & $394(76.4)$ \\
\hline & $\begin{array}{l}\text { Others, Arab expat } \\
\text { born in different Arab } \\
\text { countries }\end{array}$ & $122(23.6)$ \\
\hline \multirow[t]{4}{*}{ Marital status } & Single & $94(18.2)$ \\
\hline & Married & 352 (68.2) \\
\hline & Widowed & $45(8.7)$ \\
\hline & Divorced/separated & $25(4.8)$ \\
\hline \multirow[t]{3}{*}{ Educational level } & University education & $231(44.8)$ \\
\hline & High school diploma & $134(26.0)$ \\
\hline & Primary/middle school & $151(29.3)$ \\
\hline \multirow[t]{4}{*}{ Employment status } & Full-time & $216(41.9)$ \\
\hline & $\begin{array}{l}\text { Part-time/business } \\
\text { owner }\end{array}$ & $54(10.5)$ \\
\hline & Unemployed & $184(35.7)$ \\
\hline & Retired & $62(12.0)$ \\
\hline \multirow[t]{2}{*}{ Health literacy } & Inadequate & $313(60.7)$ \\
\hline & Adequate & 203 (39.3) \\
\hline \multirow{2}{*}{$\begin{array}{l}\text { Unanswered } \\
\text { questions }\end{array}$} & Always/sometimes & 247 (47.9) \\
\hline & Rarely/never & $269(52.1)$ \\
\hline \multirow{2}{*}{$\begin{array}{l}\text { Interest in finding } \\
\text { more information }\end{array}$} & Yes & 468 (90.7) \\
\hline & No & $48(9.3)$ \\
\hline $\begin{array}{l}\text { Main sources of } \\
\text { health information }\end{array}$ & Physicians & $428(82.9)$ \\
\hline
\end{tabular}

health information

$\begin{array}{lc}\text { Internet } & 260(50.4) \\ \text { Friends and family } & 198(38.4) \\ \text { Pharmacists } & 47(9.1)\end{array}$

$\begin{array}{lr}\text { Television } & 7(1.4) \\ \text { Magazines } & 4(0.8) \\ \text { Academic background } & 01(02)\end{array}$

*Estimated mean from the age categories using the midrange value.

in finding more information about their condition/treatment (more details in table 2). Regarding the sources of medical and health information, most participants $(83 \%)$ cited physicians as their main source of information. The Internet and friends and family members were also major sources of information $50 \%$ and $38 \%$ of participants, 


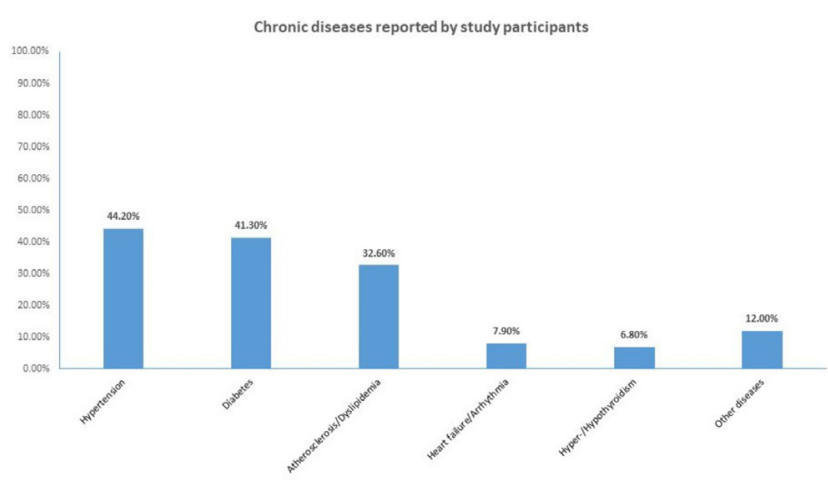

Figure 1 Participants' chronic diseases.

respectively). The most prevalent chronic diseases were hypertension, diabetes and dyslipidemia (44\%, 41\% and $32 \%$, respectively). More information regarding chronic disease can be found in figure 1 . The mean score for self-reported health status was 75.8 out of 100 (100 being the best possible health) with a SD of 18.3 points.

\section{QUESTIONNAIRE RELIABILITY}

Internal consistency reliability for the SDM nine-item scale was measured using the Cronbach's alpha coefficient, which was 0.929 (the Cronbach's alpha ranged between 0.915 and 0.929 when deleting items 1 and 5 , respectively). The ceiling effect, that is, the percentage of participants completely agreeing, on the SDM scale ranged between $16.5 \%$ for item 7 (My doctor and I thoroughly weighed the different treatment options) and $34.5 \%$ for item 9 (My doctor and I reached an agreement on how to proceed). The means of the study participants' responses on all SDM items were between 3.06 (item 7) and 3.72 (item1: My doctor made clear that a decision needs to be made). The corrected item-total correlation was lowest for item 1 (0.602) and highest for item 5 (0.831) (table 3).

\section{Factor structure}

EFA was conducted to identify the underlying structure of the SDM scale. Kaiser-Meyer-Olkin measure of sampling adequacy was 0.907 and Bartlett's test of sphericity was significant with a chi-square test value of $3413.69(\mathrm{df}=36$, $\mathrm{p}<0.0005$ ) indicating that factor analysis was adequate to the observed data. Using the PCA, only one factor had an eigenvalue above 1 and explained $64 \%$ of the total variance. Factor loadings of the nine scale items ranged between 0.676 (for item 1) and 0.875 (for item 5) (table 4).

CFA was conducted using two different models. Model 1 was a one-factor model, including the nine items of the SDM-Q-9, to confirm the single factor obtained in the EFA. Model 2 was also a monofactorial model that included items 2-9 and thus excluded item 1, which had the lowest factor loading in the EFA. Both models were adequate as they produced similar indices, with model 2 showing slightly better indices (table 5).

\section{DISCUSSION}

This study is the first to report the psychometric characteristics of the Arabic version of the SDM-Q-9. To ensure content accuracy, semantic equivalence and construct

Table 3 Items and contents of the SDM-Q-9, response distribution, means, SD and corrected item-total correlations ( $\mathrm{n}=516$ )

\begin{tabular}{|c|c|c|c|c|c|c|c|c|}
\hline $\begin{array}{l}\text { Items and content of the } \\
\text { SDM-Q-9 }\end{array}$ & $\begin{array}{l}\text { Completely } \\
\text { disagree } \\
\mathrm{N}(\%)\end{array}$ & $\begin{array}{l}\text { Strongly } \\
\text { disagree } \\
\text { N (\%) }\end{array}$ & $\begin{array}{l}\text { Somewhat } \\
\text { disagree } \\
\mathrm{N}(\%)\end{array}$ & $\begin{array}{l}\text { Somewhat } \\
\text { agree } \\
\mathrm{N}(\%)\end{array}$ & $\begin{array}{l}\text { Strongly } \\
\text { agree } \\
\mathrm{N}(\%)\end{array}$ & $\begin{array}{l}\text { Completely } \\
\text { agree (\%) } \\
\text { N (\%) }\end{array}$ & $\begin{array}{l}\text { Mean } \\
\text { (SD) }\end{array}$ & $\begin{array}{l}\text { Corrected } \\
\text { item-total } \\
\text { correlation }\end{array}$ \\
\hline $\begin{array}{l}\text { 1. My doctor made clear that a } \\
\text { decision needs to be made }\end{array}$ & $13(2.5)$ & 15 (2.9) & $40(7.8)$ & $141(27.3)$ & 135 (26.2) & $172(33.3)$ & $\begin{array}{l}3.72 \\
(1.226)\end{array}$ & $0.602^{*}$ \\
\hline $\begin{array}{l}\text { 2. My doctor wanted to know } \\
\text { exactly how I want to be involved } \\
\text { in making the decision }\end{array}$ & $25(4.8)$ & 41 (7.9) & $62(12.0)$ & $148(28.7)$ & $136(26.4)$ & $104(20.2)$ & $\begin{array}{l}3.24 \\
(1.374)\end{array}$ & $0.703^{*}$ \\
\hline $\begin{array}{l}\text { 4. My doctor precisely explained } \\
\text { the advantages and disadvantages } \\
\text { of the treatment options }\end{array}$ & $39(7.6)$ & $42(8.1)$ & 49 (9.5) & $132(25.6)$ & $132(25.6)$ & $122(23.6)$ & $\begin{array}{l}3.25 \\
(1.497)\end{array}$ & $0.715^{\star}$ \\
\hline $\begin{array}{l}\text { 5. My doctor helped me } \\
\text { understand all the information }\end{array}$ & $18(3.5)$ & $31(6.0)$ & 44 (8.5) & $136(26.4)$ & $128(24.8)$ & 159 (30.8) & $\begin{array}{l}3.55 \\
(1.348)\end{array}$ & $0.831^{*}$ \\
\hline $\begin{array}{l}\text { 8. My doctor and I selected a } \\
\text { treatment option together }\end{array}$ & 17 (3.3) & $45(8.7)$ & 52 (10.1) & 114 (22.1) & $131(25.4)$ & $157(30.4)$ & $\begin{array}{l}3.49 \\
(1.409)\end{array}$ & $0.775^{\star}$ \\
\hline $\begin{array}{l}\text { 9. My doctor and I reached an } \\
\text { agreement on how to proceed }\end{array}$ & 12 (2.3) & $33(6.4)$ & $35(6.8)$ & 113 (21.9) & $145(28.1)$ & $178(34.5)$ & $\begin{array}{l}3.71 \\
(1.304)\end{array}$ & $0.699^{*}$ \\
\hline
\end{tabular}

${ }^{*} \mathrm{P}<0.0005$. 
Table 4 Factor loadings using the principle component analysis solution

\begin{tabular}{lll}
\hline Item no & Item & Component 1 \\
\hline 1 & $\begin{array}{l}\text { My doctor made clear that a } \\
\text { decision needs to be made }\end{array}$ & 0.676 \\
\hline 2 & $\begin{array}{l}\text { My doctor wanted to know } \\
\text { exactly how I want to be involved } \\
\text { in making the decision }\end{array}$ & 0.766 \\
\hline 3 & $\begin{array}{l}\text { My doctor told me that there are } \\
\text { different options for treating my } \\
\text { medical condition }\end{array}$ & 0.802 \\
\hline 4 & $\begin{array}{l}\text { My doctor precisely explained } \\
\text { the advantages and } \\
\text { disadvantages of the treatment } \\
\text { options }\end{array}$ & 0.779 \\
\hline 5 & $\begin{array}{l}\text { My doctor helped me understand } \\
\text { all the information }\end{array}$ & 0.875 \\
\hline 6 & $\begin{array}{l}\text { My doctor asked me which } \\
\text { treatment option I prefer }\end{array}$ & 0.840 \\
\hline 7 & $\begin{array}{l}\text { My doctor and I thoroughly } \\
\text { weighed the different treatment } \\
\text { options }\end{array}$ & 0.849 \\
\hline 9 & $\begin{array}{l}\text { My doctor and I selected a } \\
\text { treatment option together }\end{array}$ & 0.832 \\
\hline & $\begin{array}{l}\text { My doctor and I reached an } \\
\text { agreement on how to proceed }\end{array}$ & 0.766 \\
\hline
\end{tabular}

validity, international multiphase translation guidelines were followed in the processes of translation and validation of the Arabic version SDM-Q-9. ${ }^{29}$ The newly translated Arabic version of the SDM-Q-9 is the first psychometrically tested tool that assesses SDM process from Arabicspeaking patient's perspective.

Reliability and validity analysis of the Arabic version of the SDM-Q-9 scale revealed that the translated tool was reliable and valid. Cronbach's alpha (0.929) indicated high internal consistency of the scale with all items showing adequate values for corrected item-total correlations that ranged between 0.602 (for item 1) and 0.831 (for item 5). Results pertaining to scale reliability and corrected item-total correlations were comparable to those reported for the German version by Kriston et $a l^{25}$ and the Spanish version by De las Cuevas $e t a l$ who

\begin{tabular}{llllll}
\hline Table 5 & \multicolumn{6}{c}{ Results of the confirmatory factor analysis } \\
\hline Model & $\chi^{2}$ & CFI & GFI & RMR & RMSEA \\
\hline Model 1 & $500.8^{*}$ & 0.998 & 0.991 & 0.029 & 0.033 \\
Model 2 & $373.0^{*}$ & 0.998 & 0.992 & 0.027 & 0.032 \\
\hline
\end{tabular}

Model 1-includes all nine items.

Model 2-excludes item 1.

${ }^{*} \mathrm{P}<0.0005$.

$\mathrm{CFI}$, comparative fit index; GFI, goodness of fit index; RMR, root mean square residual; RMR and RMSEA <0.05; RMSEA, root mean square error of approximations recommended values: $\mathrm{CFI}$ and $\mathrm{GFI}>0.90$ reported Cronbach's alpha values of 0.94 and 0.89 and corrected item-total correlations from 0.69 to 0.85 , and 0.52 to 0.82 , respectively. ${ }^{30}$ Similar results have also indicated good reliability for the SDM-9 scale for the Dutch and Hebrew versions. ${ }^{22} 3132$

In this study, EFA revealed a one-factor solution explaining $64 \%$ of the total variance. This result showed that, unlike the Spanish version of the SDM-Q-9 that resulted in a two-factor-solution, ${ }^{30}$ the validation of Arabic version of the SDM scale was consistent with those of the original version ${ }^{25}$ and the Hebrew version ${ }^{22}$ of the scale that showed a unidimensional structure of the SDM scale. All items of the Arabic version of the SDM scale showed adequate factor loadings that ranged between 0.676 for item 1 and 0.875 for item 5 . In our study, two single-factor models were tested in the CFA. Model 1 included all nine items of the SDM scale while model 2 excluded item 1 as it had lowest factor loading in the EFA, similar to what was reported by De las Cuevas et al. ${ }^{30}$ Both models resulted in very similar indices indicating adequate fit with the data. The bivariate correlation matrix among all scale items showed good correlation coefficient values ranging between 0.402 and 0.810 with the weakest ones being between item 1 and the other items. This observation has been also reported in other studies where item 1 showed lower values for correlations as well as factor loadings. ${ }^{25} 30$

\section{Methodological consideration}

Some limitations of this study need to be taken into account. The convenience sampling may not be representative of the entire population attending secondary healthcare settings. However, the aforementioned limitation is likely mitigated considering the large sample size and the diversity of study participants (a mix of both Emirati and Arab expat born in different Arab countries, and varying educational characteristics). Caution must be exercised when interpreting results; the use of a self-reported measure in this study does not eliminate the possibility of an inaccurate recall of respondents' experiences, opinions and behaviour. Another limitation of this study lies in conducting EFA and CFA using the same sample. This could be presenting duplicate analyses that aim to first discover the underlying factors of the SDM9 tool and then confirm these factors using the same sample subjects. EFA and CFA analyses ideally should have been conducted on separate samples, yet, in this study both analyses were run using the same subjects. One major strength of this work is the potential for the Arabic version of SDM-Q-9 (perhaps with minor adaptations to adjust to regional variations in the language) to be used by the 407 million people who make up the populations of all the Arab states. In addition, the Arabic version also can be of use for Arabic-speaking immigrants in other regions of the world, for example, Europe, North America and Australia. The sample size exceeded the minimum needed number, which is another strength of this study. 


\section{CONCLUSION}

The study results suggest that SDM-Q-9 in its Arabic version is suitable for use in the UAE and the other 21 state members of the Arab League where Arabic is the official language, capitalising on linguistic and cultural similarities between these Arabic-speaking countries. The Arabic version of the SDM-Q-9 may be used to evaluate the effectiveness of intervention and strategies that aim to enhance SDM in healthcare services and research across various settings. The use of the questionnaire in medical encounters could provide a valuable reminder to healthcare professionals to think about SDM in their consultations and monitor their own practice to ensure patients' preferences and values will guide treatment decisions (where appropriate). Furthermore, the Arabic version of the SDM-Q-9 can be a useful tool in epidemiological and clinical studies, resulting in better insight into how best to implement SDM in clinical practice in Arabic-speaking countries aiming at improving patient care.

Acknowledgements The authors would like to thank study participants for taking the time to complete study questionnaire, and sharing their 'real' perspectives and opinions. We also would like to acknowledge the support of field research teams for their efforts in data collection (Aisha Ali, Fatima Alzaabi and Alharah Ali).

Contributors HTA designed the study, supervised data collection process, assisted with data analysis, wrote, reviewed and edited the entire manuscript. KM contributed to the discussion and edited the manuscript. AH assisted significantly with data analysis and edited the manuscript. IS assisted with designing of the study, reviewed the methods and data analysis and edited the manuscript.

Funding This work was supported by an internal grant from the Sharjah Institute for Medical Research, University of Sharjah, United Arab Emirates.

Competing interests None declared.

Patient consent for publication Not required.

Ethics approval Ethical approval to conduct the study was obtained from the University of Sharjah Research Ethics Committee (REC-17-09-28-01-S).

Provenance and peer review Not commissioned; externally peer reviewed.

Data sharing statement All data relevant to the study are included in the article or uploaded as supplementary information.

Open access This is an open access article distributed in accordance with the Creative Commons Attribution Non Commercial (CC BY-NC 4.0) license, which permits others to distribute, remix, adapt, build upon this work non-commercially, and license their derivative works on different terms, provided the original work is properly cited, appropriate credit is given, any changes made indicated, and the use is non-commercial. See: http://creativecommons.org/licenses/by-nc/4.0/.

\section{REFERENCES}

1. Clayman ML, Bylund CL, Chewning B, et al. The Impact of Patient Participation in Health Decisions Within Medical Encounters: A Systematic Review. Med Decis Making 2016;36:427-52.

2. Joseph-Williams N, Lloyd A, Edwards A, et al. Implementing shared decision making in the NHS: lessons from the MAGIC programme. BMJ 2017;357:j1744.

3. Elwyn G, Frosch D, Thomson R, et al. Shared decision making: a model for clinical practice. J Gen Intern Med 2012;27:1361-7.

4. Légaré F, Stacey D, Turcotte S, et al. Interventions for improving the adoption of shared decision making by healthcare professionals. Cochrane Database Syst Rev 2014;9:Cd006732.

5. Simmons M, Hetrick S, Jorm A. Shared decision-making: benefits, barriers and current opportunities for application. Australas Psychiatry 2010;18:394-7.

6. Gärtner FR, Bomhof-Roordink H, Smith IP, et al. The quality of instruments to assess the process of shared decision making: $A$ systematic review. PLoS One 2018;13:e0191747.
7. Elwyn G, Durand MA, Song J, et al. A three-talk model for shared decision making: multistage consultation process. BMJ 2017;359:j4891.

8. Chen J, Mullins CD, Novak P, et al. Personalized Strategies to Activate and Empower Patients in Health Care and Reduce Health Disparities. Health Educ Behav 2016;43:25-34.

9. Hofstede SN, van Bodegom-Vos L, Wentink MM, et al. Most important factors for the implementation of shared decision making in sciatica care: ranking among professionals and patients. PLoS One 2014;9:e94176.

10. Eliacin J, Salyers MP, Kukla M, et al. Factors influencing patients' preferences and perceived involvement in shared decision-making in mental health care. J Ment Health 2015;24:24-8.

11. Hughes TM, Merath K, Chen Q, et al. Association of shared decisionmaking on patient-reported health outcomes and healthcare utilization. Am J Surg 2018;216:7-12 https://doi.org/.

12. Légaré F, Witteman HO. Shared decision making: examining key elements and barriers to adoption into routine clinical practice. Health Aff 2013;32:276-84.

13. Joseph-Williams N, Elwyn G, Edwards A. Knowledge is not power for patients: a systematic review and thematic synthesis of patientreported barriers and facilitators to shared decision making. Patient Educ Couns 2014;94:291-309.

14. Hoffman TC, Légaré F, Simmons MB, et al. Shared Decision Making: What is it and why should clinicians bother? Medical Journal of Australia 2014;201:35-9.

15. Mc Namara KP, Breken BD, Alzubaidi HT, et al. Health professional perspectives on the management of multimorbidity and polypharmacy for older patients in Australia. Age Ageing 2017;46:291-9.

16. Shay LA, Lafata JE. Where is the evidence? A systematic review of shared decision making and patient outcomes. Med Decis Making 2015;35:114-31.

17. Durand MA, Carpenter L, Dolan H, et al. Do interventions designed to support shared decision-making reduce health inequalities? A systematic review and meta-analysis. PLoS One 2014;9:e94670.

18. Armstrong MJ. Shared decision-making in stroke: an evolving approach to improved patient care. Stroke Vasc Neurol 2017;2:84-7.

19. Veroff D, Marr A, Wennberg DE. Enhanced support for shared decision making reduced costs of care for patients with preferencesensitive conditions. Health Aff 2013;32:285-93.

20. Algaze CA, Wood M, Pageler NM, et al. Use of a Checklist and Clinical Decision Support Tool Reduces Laboratory Use and Improves Cost. Pediatrics 2016;137:e20143019.

21. Ballesteros J, Moral E, Brieva L, et al. Psychometric properties of the SDM-Q-9 questionnaire for shared decision-making in multiple sclerosis: item response theory modelling and confirmatory factor analysis. Health Qual Life Outcomes 2017;15:79.

22. Doherr H, Christalle E, Kriston L, et al. Use of the 9-item Shared Decision Making Questionnaire (SDM-Q-9 and SDM$\mathrm{Q}$-Doc) in intervention studies-A systematic review. PLoS One 2017;12:e0173904

23. The 9-item Shared Decision Making Questionnaire SDM-Q-9 / SDMQ-Doc: PATIENT als PARTNER. http://www.patient-als-partner.de/ index.php?article_id=20\&clang=2/ (accessed 15 July, 2018).

24. www.sdmq9.org. [2018]. Available from: http://www.patient-alspartner.de/index.php?article_id=20\&clang=2/ accessed Jan 142018.

25. Kriston L, Scholl I, Hölzel L, et al. The 9-item Shared Decision Making Questionnaire (SDM-Q-9). Development and psychometric properties in a primary care sample. Patient Educ Couns 2010;80:94-9.

26. AlHaqwi Al, AIDrees TM, AIRumayyan A, et al. Shared clinical decision making. A Saudi Arabian perspective. Saudi Med J 2015;36:1472-6.

27. Peterson PN, et al. Health Literacy and Outcomes Among Patients With Heart Failure. JAMA 2011;305:1695-701.

28. Corp IBM. Released 2016. IBM SPSS Statistics for Windows, Version 24. Armonk, NY: IBM Corp 2016.

29. Beaton DE, Bombardier C, Guillemin F, et al. Guidelines for the process of cross-cultural adaptation of self-report measures. Spine 2000;25:3186-91.

30. De las Cuevas C, Perestelo-Perez L, Rivero-Santana A, et al. Validation of the Spanish version of the 9-item Shared DecisionMaking Questionnaire. Health Expect 2015;18:2143-53.

31. Rodenburg-Vandenbussche S, Pieterse AH, Kroonenberg PM, et al. Dutch Translation and Psychometric Testing of the 9-Item Shared Decision Making Questionnaire (SDM-Q-9) and Shared Decision Making Questionnaire-Physician Version (SDM-Q-Doc) in Primary and Secondary Care. PLoS One 2015;10:e0132158.

32. Zisman-Ilani Y, Roe D, Scholl I, et al. Shared Decision Making During Active Psychiatric Hospitalization: Assessment and Psychometric Properties. Health Commun 2017;32:126-30. 